\title{
Производство салата - опыт в Московской области
}

\begin{abstract}
М.В. Шатилов, М.И. Иванова, О.А. Разин, Т.Н. Сурихина, М.В. Кузякин, Е.С. Соколова, В.С. Буканов

B статье приведен анализ рынка салата посевного (Lactuca sativa L.), как одной из самых экономически важных листовых овощных культур. Показаны показатели мирового производства салата, включая информацию о странах, которые имеют существенную долю в общемировом производстве. Описан процесс возделывания и проанализированы экономические показатели на примере ООО «Веселый агроном», выращивающего салаты в Дмитровском районе Московской области.
\end{abstract}

Ключевые слова: салаты, производство, экономика.

алат посевной (Lactuca sativa L.) считается одной из самых экономически важных листовых овощных культур в мире [1]. Оздоровительные свойства салата определяются высоким содержанием антиоксидантных соединений, прежде всего витамина С и полифенолов, а также клетчатки [2]. В производстве выращивают несколько морфотипов салата, но наиболее распространенными являются ромэн, листовой, кочанные хрустящий и маслянистый. Выращивание морфотипов и разновидностей салата зависит от стратегии рынка и коммерческих требований [3, 4].

По данным ФАО, в 2017 году салаты производили в 106 странах. Приведем производственные показатели стран, доля которых в общемировом валовом сборе составляет более $1 \%[5]$.

Большая часть валового сбора и посевной площади (75\%) приходится на Китай, Индию и США.

Более половины мировой посевной площади приходится на Китай $(51,6 \%)$. За исследуемый период в стране наблюдается рост 1-2\% ежегодно. На долю Индии приходится 14\% посевной площади, а в США в полтора раза меньше - 9,1\%.

Валовой сбор салата в Китае больше, чем у всех остальных стран вместе взятых, его доля в общемировом сборе составляет 56,4\%.Второе место занимают США $(14,3 \%)$, это связано с низкой - в 3,5 раза меньше среднемировой - урожайностью в Индии, доля которой составила $4,1 \%$.

В качестве примера производства салатов в России рассмот- рим мелкотоварное хозяйство ООО «Веселый агроном».

Компания «Веселый агроном» расположена на территории Московской области в Дмитровском районе с. Орудьево, имеет ярко выраженную сезонность. Производственный цикл длится с марта по октябрь. Компания производит пять основных видов салата открытого грунта: Айсберг, Романо, Фриссе, Радиччио, Лолло-Россо. Для производства мы используем голландские гибриды. Компания поставляет продукцию с июня по октябрь, для выполнения контрактных обязательств и соблюдения жесткого графика поставок используется конвейерный метод производства. Конвейер разбит на 14 производственных циклов (сроков). Один производственный цикл включает в себя следующие операции.

Для набивки торфом пластиковых кассет, посева и полива используют автоматизированную линию Urbinati Kappa 65 c.

Кассеты заполняют просеянным торфом (Кеккила, Пидструп, Классман) нейтральной кислотности ( $\mathrm{pH} \approx 7)$, смешанным с агроперлитом в соотношении 8:2. Проверку приобретенного торфа на содержание макроэлементов проводят в агрохимической лаборатории. В наполненных субстратом кассетах маркером выдавливают углубления в центрах ячеек и сеялкой производят посев семян. Затем на инспекционном столе проверяют, чтобы в центре каждой ячейки находилось одно семечко, и кассету засыпают агроперлитом до полного покрытия семян и перегородок между кассетами. После этого кассету поливают мелко распыленной водой до полного промачивания.
Посев проводят по специальному графику под контролем агронома (табл. 1).

После посева кассеты устанваливают на поддон в шахматном порядке друг на друга с маркировкой сорта и даты по принципу слоенного пирога и помещают в камеру проращивания. После заполнения поддона его плотно обматывают стрейч-лентой, внутри устанавливают термометр для контроля температуры. В результате мы получаем среду с повышенной влажностью. Поддон оставляют в помещении с контролируемой температурой $15-17^{\circ} \mathrm{C}$ на 48 ч.

Рассаду в защищенном грунте выращивают в двухслойных пленочных теплицах производства компании «ИМПОТЭК» с климатическим контролем и автоматизированной итальянской системой полива Urbinati. Температурный режим: 15$25{ }^{\circ} \mathrm{C}$ днем и $10-15{ }^{\circ} \mathrm{C}$ ночью в зависимости от периода вегетации и внешних погодных условий. Период роста в защищенном грунте составляет от 25 до 45 суток, в зависимости от срока посадки, сорта и внешних условий: длины светового дня, температуры почвы и воздуха.

Система подкормки салата в зависимости от состояния рассады и внешних условий: первая подкормка азотно-фосфорная, вторая - фосфорно-калийная, третья - кальциево-магниевая.

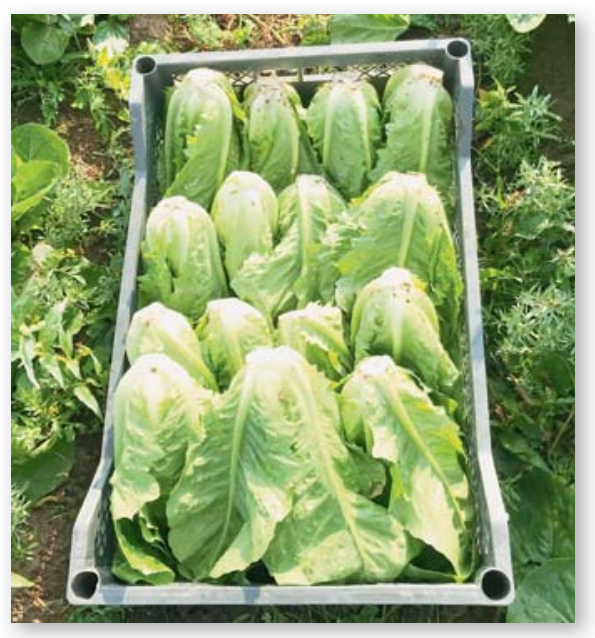


Таблица 1. График посева салата в 000 «Веселый агроном», на примере 2019 года

\begin{tabular}{|c|c|c|c|c|c|c|c|c|c|c|c|}
\hline \multirow{2}{*}{ Сорт } & \multicolumn{11}{|c|}{ Дата посева } \\
\hline & 27.03 & 04.04 & 11.04 & 18.04 & 25.04 & 02.05 & 09.05 & 16.05 & 23.05 & 30.05 & 06.06 \\
\hline Мирет & + & + & & & & & & & & & \\
\hline Даймонд & & + & + & + & + & + & + & + & + & + & + \\
\hline Диамантинас & & + & + & + & + & + & + & + & + & + & + \\
\hline \multicolumn{12}{|l|}{ Платинос } \\
\hline $\begin{array}{l}\text { Квинтус } \\
\text { (Романо) }\end{array}$ & + & + & + & + & + & + & + & + & + & + & + \\
\hline $\begin{array}{l}\text { Сигал } \\
\text { (Фриссе) }\end{array}$ & + & + & + & + & + & + & + & + & + & + & + \\
\hline Туска & + & + & + & + & + & + & + & + & + & + & + \\
\hline Леонардо & & & & + & + & + & + & & & & \\
\hline
\end{tabular}

Высадка рассады в открытый грунт - механизированном методом на рассадопосадочных машинах Ferrari FX multipla. Рабочая бригада состоит из тракториста-механизатора трактора мощностью не более 90 л/с и рассадопасадочной машины с двумя операторами и двумя контролерами (общее количество 5 человек). Норма высадки одной бригады составляет 500 кассет 144 ячейки в смену. Два работника на рассадопосадочной машине аккуратно извлекают растения из ячеек и опускают в ячейки высаживающего аппарата, другие два работника идут следом за машиной и поправляют высаженную рассаду. При необходимости после посадки растения поливают для лучшей приживаемости. Норму полива устанавливает агроном.

Основа в работах по уходу за посадками салата - ежедневный мониторинг состояния растений, почвы, погодных условий. К основным элементам ухода за посадками относятся прополка, полив и подкормка минеральными удобрениями, корневые и некорневые подкормки. Подкормки рассады после высадки в открытый грунт следующие: первая некорневая - фосфорная, вторая корневая кальциевой селитрой, третья некор- невая - азотная, четвертая корневая - аммиачной селитрой, пятая некорневая - калийная.

С сорняками необходимо начинать борьбу в фазе «белой ниточки», когда они не вышли на поверхность. Для этого нужно с помощью полива создать условия отсутствия почвенной корки, чтобы поверхность почвы была влажной и «мягкой». В это время необходимо вручную прорыхлить поверхность гряд, не подваливая почву к растениям, чтобы не создавать условий для развития болезней салата. Последующие работы по борьбе с сорной растительностью сводятся к регулярному удалению сорняков вручную.

Необходимость полива салата определяется погодными условиями и состоянием растений. Общее водопотребление составляет 140 мм. Поливная норма может колебаться от 6 до 15 мм. В жаркое время необходимо поливать в ночное время, чтобы не появился внутренний некроз. С момента формирования кочанов частоту полива нужно уменьшить для предотвращения развития гнилей. Полив - машиной Irrimec.

Убирают салат вручную в зависимости от заказа и спецификации клиента. С момента высадки расса-

Таблица 2. Экономические показатели 000 “Веселый агроном» в Дмитровском районе Московской области, 2016-2018 годы

\begin{tabular}{|c|c|c|c|}
\hline \multirow{2}{*}{ Показатель } & \multicolumn{3}{|c|}{ Год } \\
\hline & 2016 & 2017 & 2018 \\
\hline \multicolumn{4}{|c|}{ Выручка от реализации продукции, тыс. р. } \\
\hline всего, & 25439 & 26139 & 35002 \\
\hline на 1 га & 424 & 373 & 565 \\
\hline на 1 т & 39 & 40 & 58 \\
\hline \multicolumn{4}{|c|}{ Прибыль от реализации продукции, тыс. p. } \\
\hline всего, & 8339 & 7839 & 14972 \\
\hline на 1 га & 139 & 112 & 242 \\
\hline на $1 \mathrm{~T}$ & 13 & 12 & 25 \\
\hline
\end{tabular}

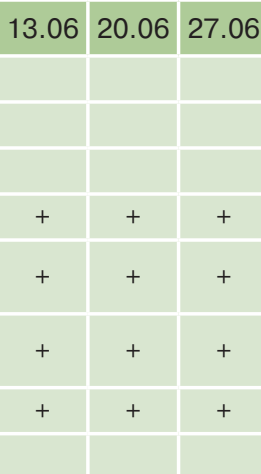

ды до уборки (срезки кочанов) проходит в среднем 45 суток. Реализация салата - с поля.

Оптимальные условия хранения салата - при $4{ }^{\circ} \mathrm{C}$, в компании отсутствуют холодильная камера хранения (склад сырья).

Прав ильны й производственный процесс выглядит следующим образом. Уборка начинается рано утром. Кочан срезают острым ножом и удаляют два наружных листа, затем его осматривают. Кочаны с признаками повреждений и заболеваний бракуют. Здоровые кочаны свободно укладывают в ящики кочерыгой вниз. и в течение 30 минут доставляют на склад сырья. Погрузку и разгрузку тары с салатом производится аккуратно, без рывков и ударов, чтобы не допускать поломки тары и повреждения продукции. Там он помещается в Вакуум-кулер, где происходит шоковое охлаждение в «клетке растения» до 2-4 в течение 15-30 минут. Что приводит к увеличению сроков хранения и реализации. В этот период салат хранится в холодильной камере при $+4{ }^{\circ} \mathrm{C}$.

Формирование хорошего урожая зависит от качественной подготовки почвы, которая начинается с осенней вспашки и включает в себя осеннюю вспашку, внесение органического удобрения, весеннюю разделку почвы пропашным культиватором, внесение минеральных удобрений, нарезку гряд, культивация с внесением удобрения в вегетационный период.

Рассмотрим показатели производства салатов и его эффективности в ООО «Веселый агроном» Дмитровского района Московской области (табл. 2, 3).

Посевная площадь салатов возросла с 54 га в 2016 году до 62 га в 2018 году. Несмотря на увеличение посевной площади, валовой сбор салатов снизился - это произошло изза неблагоприятных погодных условий, - но остался на уровне более 600 т в каждом году рассматриваемого периода. Средняя урожайность за три года составила 10 т/га.

Выручка от реализации продукции увеличилась с 25,4 млн р. в 2016 году до 35,0 млн р. в 2018 году: на 1 га - с 424 до 565 тыс. р.; на 1 т реализованной про- 
Таблица 3. Производственные показатели в 000 «Веселый агроном» по годам и видам салата, 2016-2018 годы

\begin{tabular}{|c|c|c|c|c|c|c|c|c|c|}
\hline \multirow{3}{*}{$\begin{array}{c}\text { Вид } \\
\text { продукции }\end{array}$} & \multicolumn{9}{|c|}{ Год } \\
\hline & \multicolumn{3}{|c|}{2016} & \multicolumn{3}{|c|}{2017} & \multicolumn{3}{|c|}{2018} \\
\hline & $\begin{array}{c}\text { площадь, } \\
\text { га }\end{array}$ & $\begin{array}{l}\text { валовой, } \\
\text { сбор т }\end{array}$ & $\begin{array}{c}\text { урожайность, } \\
\text { т/га }\end{array}$ & $\begin{array}{c}\text { площадь, } \\
\text { га }\end{array}$ & $\begin{array}{c}\text { валовой } \\
\text { сбор, т }\end{array}$ & $\begin{array}{c}\text { урожайность, } \\
\text { т/га }\end{array}$ & $\begin{array}{c}\text { площадь, } \\
\text { га }\end{array}$ & $\begin{array}{c}\text { валовой } \\
\text { сбор, т }\end{array}$ & $\begin{array}{c}\text { урожайность, } \\
\text { т/га }\end{array}$ \\
\hline Айсберг & 43,10 & 525,70 & 12,20 & 54,10 & 461,00 & 8,52 & 49,00 & 503,00 & 10,27 \\
\hline Романо & 4,50 & 54,90 & 12,20 & 6,30 & 70,00 & 11,11 & 6,10 & 54,00 & 8,85 \\
\hline Фриссе & 3,20 & 38,80 & 12,13 & 3,20 & 30,00 & 9,38 & 2,10 & 10,00 & 4,76 \\
\hline Лолла-Россо & 0,85 & 5,10 & 6,00 & 0,50 & 3,00 & 6,00 & 0,70 & 1,80 & 2,57 \\
\hline Радиччио & 2,50 & 20,40 & 8,16 & 1,90 & 12,00 & 6,32 & 1,30 & 4,40 & 3,38 \\
\hline Литл-Джем & - & - & - & - & - & - & 0,20 & 0,90 & 4,50 \\
\hline $\begin{array}{l}\text { Капуста } \\
\text { белокочанная }\end{array}$ & - & - & - & - & - & - & 0,50 & 7,60 & 15,20 \\
\hline $\begin{array}{l}\text { Капуста } \\
\text { китайская }\end{array}$ & - & - & - & 2 & 29 & 14,5 & 2 & 26 & 13 \\
\hline
\end{tabular}

дукции - с 39 до 58 тыс. р. Прибыль от реализации возросла за 3 года с 8,3 млн р. в 2016 году до 15,0 млн р. в 2018 году. Прибыль на 1 га возросла со 139 до 242 тыс. р., на 1 т с 13 до 25 тыс. р. В структуре затрат семена и рассада составляют $24 \%$, а доля заработной платы - 29\%.

Рост выручки связан с повышением оптовой отпускной цены на салаты сортов Айсберг на $49 \%$ и Романо на 30\% (табл. 4). В структуре валового сбора они занимают долю в 83 и 9\% соответственно. Таким образом, опыт ООО «Веселый агроном» Дмитровского района Московской области, мелкотоварного производителя, свидетельствует о том, что в условиях Московской области возможно организовать стабильное поступление салата (650 т) с прибылью не менее 112 тыс. р. на 1 га.

\section{Библиографический список}

1.Солдатенко А.В., Пивоваров В.Ф., Разин А.Ф. Мещерякова Р.А., Шатилов М.В., Иванова М.И., Тактарова С.В., Разин О.А. Экономика овощеводства: состояние и современность // Овощи России. 2018. № 5 (43). C. $63-68$.

2.Materska M., Olszówka K., Chilczuk B., Stochmal A. Pecio Ł., Pacholczyk Sienicka B., Piacente S., Pizza C., Masullo M. Polyphenolic profiles in lettuce (Lactuca sativa L.) after $\mathrm{CaCl}_{2}$ treatment and cold storage // European Food Research and Technology (2019) 245. Pp. 733-744 https://doi.org/10.1007/s00217-018-3195-0

Таблица 4. Среднегодовые цены реализации продукции по сортам, р/кг

\begin{tabular}{|l|c|c|c|}
\hline \multirow{2}{*}{ Вид продукции } & \multicolumn{3}{|c|}{ Год } \\
\cline { 1 - 4 } & 2016 & 2017 & 2018 \\
\hline Айсберг & 38,36 & 41,28 & 57,19 \\
\hline Романо & 58,81 & 60,81 & 76,50 \\
\hline Фриссе & 53,89 & 53,40 & 57,14 \\
\hline Лола & 78,84 & 90,24 & 82,61 \\
\hline Род & 101,92 & 99,75 & 108,50 \\
\hline Капуста пекинская & - & 19,00 & 31,90 \\
\hline Капуста белокочанная & - & 15,03 & 10,20 \\
\hline
\end{tabular}

З.Иванова М.И., Кашлева А.И., Алексеева К.Л., Давлетбаева О.Р. Салат: многообразие разновидностей и сортов // Картофель и овощи. 2017. № 5. С. 22-24.

4.Иванова М.И., Кашлева А.И., Алексеева К.Л. Салат: биология и технология // Картофель и овощи. 2017. № 6. С. $23-25$.

5.Материалы ФАО [Электронный ресурс]. URL: http:// www.fao.org/faostat/ru/\#data/QC. Дата обращения: 15.06.18

\section{Об авторах}

Шатилов Максим Витальевич, канд. с. - х. наук, н.с. отдела экономики, Всероссийский научно-исследовательский институт овощеводства филиал ФГБНУ «Федеральный научный центр овощеводства» (ВНИИО филиал ФГБНУ ФНЦО).

E-mail:vniioh@yandex.ru

Иванова Мария Ивановна, доктор

c. - х. наук, проф. РАН, гл. н.с. отдела селекции и семеноводства, ВНИИО филиал ФГБНУ ФНЦО.

E-mail: ivanova_170@mail.ru

Разин Олег Анатольевич, канд. С. х. наук, гл.н.с., ФГБНУ «Федеральный научный центр овощеводства»

Сурихина Татьяна Николаевна, м.н.с. отдела экономики, ВНИИО филиал ФГБНУ ФНЦО

E-mail: 9153756862@mail.ru

Кузякин Максим Владимирович, генеральный директор, ООО «Веселый агроном»
Соколова Екатерина Сергеевна, главный агроном, ООО «Веселый агроном»

Буканов Владимир Сергеевич, финансовый директор, ООО «Веселый агроном»

Production of salads - the experience of bewerberportal Moscow region M.v. Shatilov, $P h D$, research fellow of department of economics, All-Russian Research Institute of Vegetable Growing branch of Federal State Budgetary Institution Federal Scientific Centre of Vegetable Growing (ARRIVG - FSBI FSCVG).E-mail:vniioh@yandex.ru M.I. Ivanova, DSc., professor RAS, chief research fellow, department of breeding and seed growing, ARRIVG - FSBI FSCVG. E-mail: ivanova170@mail.ru O.A. Razin, PhD, chief research fellow, Federal Scientific Centre of Vegetable Growing

T.N. Surikhina, junior research fellow, department of economics, ARRIVG - FSBI FSCVG. E-mail: 9153756862@mail.ru M.V. Kuzyakin, director general, LLC Vesyolyi Agronom

E.S. Sokolova, chief agronomist, LLC Vesyolyi Agronom

V.S. Bukanov, chief financial officer. LLC Vesyolyi Agronom

Summary. The article presents an analysis of the market of lettuce (Lastuca sativa L.) as one of the most economically important leafy vegetable crops. The production indicators of the world salad production are shown, including information about the countries that have a significant share in the global production. The process of production is described and economic indicators are analyzed on the example of LLC Vesyolyi Agronom growing salads in the Dmitrov district of the Moscow region.

Keywords: lettuce, production, economics. 